\title{
PROGRAMA DE SAÚDE NA ESCOLA: ATUAÇÃO DO MÉDICO VETERINÁRIO EM AÇÕES INTERPROFISSIONAIS NO MUNICÍPIO DE SANTA MARIA - RS
}

\author{
SCHOOL HEALTH PROGRAMME: THE VETERINARIAN'S ROLE IN \\ INTERPROFESSIONAL PRATICE IN SANTA MARIA CITY, RIO GRANDE DO SUL \\ STATE, BRAZIL
}

\author{
J. S. P. VASCONCELLOS*1, S. A. BOTTON², F.S.F.VOGEL ${ }^{2}$, L. A. SANGIONI²
}

\section{RESUMO}

O Programa de Saúde na Escola (PSE) tem por objetivo a articulação permanente da saúde e da educação visando a melhoria da qualidade de vida da população. O Médico Veterinário pode contribuir apoiando os profissionais das Estratégias de Saúde da Família (ESF) nos cuidados à saúde dos escolares. Este projeto buscou a identificação, prevenção, indução da corresponsabilidade e controle de riscos, causados pelas inter-relações do meio ambiente e saúde. Foram realizadas duas oficinas de trabalho, " $1^{\mathrm{a}}$ e $2^{\mathrm{a}}$ Feiras de Saúde" na Escola Diácono João Luis Pozzobon, envolvendo 416 alunos do ensino fundamental, em novembro de 2014 e maio de 2015, no município de Santa Maria - RS. As temáticas abordadas foram "Saúde Ambiental" e "Doenças Negligenciadas e em Eliminação" respectivamente. Para isto, foram realizadas reuniões com os professores e profissionais da saúde para a construção de planos, condutas e abordagens integrativas e complementares, que deram origem ao formato expositivo das atividades realizadas. O trabalho de promoção da saúde intersetorial e interdisciplinar, visando a realidade ambiental da comunidade escolar favorece a transformação social para a qualidade de vida dos alunos, garantindo o direito fundamental ao meio ambiente das gerações presentes e futuras. Estas ações permitiram o fortalecimento da Atenção Básica. Esta iniciativa piloto foi ampliada e serviu de modelo para outras ESF do município. O PSE é considerado uma das políticas de saúde e educação prioritárias, constando nas ferramentas de planejamento estratégico e gestão do município, embora ainda não contemplem a totalidade das escolas. O Médico Veterinário é de extrema valia em ações pontuais e interprofissionais no PSE, contribuindo ativamente para o fortalecimento da atenção à saúde escolar. Ações nas escolas que ocorriam de forma isolada, hoje se constituem em ações periódicas, em consonância ao conceito de promoção da saúde. Salienta-se a importância de expansão do programa para todo o município.

PALAVRAS-CHAVE: PSE. SAÚDE AMBIENTAL. MEDICINA VETERINÁRIA PREVENTIVA. MULTIDISCIPLINAR. INTERSETORIAL.

AGRADECIMENTOS: Agradecemos à CAPES (Coordenação de Aperfeiçoamento de Pessoal de Nível Superior) pela concessão da bolsa de estudos.

ÁREA TEMÁTICA: SAÚDE PÚBLICA. 